\title{
1. Introduction to Boundaries and Restricted Places: The Immured Space
}

Balkiz Yapicioglu and Konstantinos Lalenis

\section{WHY IMMURED?}

In aiming to explain the scope of the book, and to introduce the reader to the perception of immured spaces and the theoretical framework covering it, it would be useful to recall the events which triggered the related discussion.

The refugee crisis, which haunted Europe before COVID 19, was at its peak at the beginning of 2016. The closure of borders which followed the agreement between EU and Turkey ${ }^{1}$ resulted in high numbers of refugees trapped within national borders of European countries which in no way were their desired destinations. New walls were emerging everywhere to prevent the refugees' irregular movements through national territories, and their search for freedom usually ended in detention centres bounded by fences. The refugees were running away from restrictive boundaries and prison walls imposed by war, poverty, and discrimination based on race, ethnicity, gender, sexual orientations and so on, and they ended up having to face the same boundaries and walls, from which they were trying to escape. This tragic irony, and its effect on the resilience of our cities, triggered intense discussions among a group of academics that happened to meet in 2016, in Volos, Greece. In the development of our discussion, there was also the realization of the variety of boundaries, walls and separating barriers, existing in our cities, which needed to be explored more in depth. Spaces defined by the above, such as divided by physical walls, hosting and enforcing segregation, spaces that are accessed by only certain groups of people, and spaces that are isolated behind the veil of the unknown seem to be significant elements in defining the contemporary city. So, the aim of this collective effort is to set a general theoretical framework compiling definitions and analyses of the element which separates and/ or divides space, to investigate the wide variety of effects that this element imposes on space, and to analyse the impacts that any opening of barriers, boundaries and so on, or the imposition of new ones, can bring to the surrounding places. This is attempted through an exposition of perceptions of 
academics and practitioners about borders/boundaries/walls/barriers - in short, immured spaces, stemming from experiences or research from different parts of the world. In turn, this contributes to the global sense of boundaries and restricted places.

\section{BOUNDARIES AND RESTRICTED PLACES}

The wall as a physical division can be considered as the archetype of boundaries in the human environment. The wall, historically, has been an important element of city planning as a defence mechanism against intrusion and thus, limiting access to the other. The degree of access allowed, was in accordance to the threat represented by the other. In his paramount work, 'The City in History', historian Lewis Mumford describes that the limit (border/boundary) that originally defined the physical town or city-state, was the wall, mainly with its militaristic purpose. Walls of different cultures all served this same primary purpose and were constructed in innumerable ways. In fact, certain cities are referred to as Walled Cities, like Jericho in the West Bank, in Israel, Dubrovnik in Croatia, York in the UK, Harar in Eastern Ethiopia and many others. However, historically, the walls of the citadels preceded the walls of the cities, and according to Mumford (1961), they were not initially built for defence but were rather a storage point of food (grain and etc.). Their character as a final line of defence was developed later, when war became an established institution. The fact that, according to Mumford, the walls were initially built 'to define the sacred limits of the temenos, and to keep at bay evil spirits rather than inimical men' (p.36) is indicative of the protective character of the wall, through times.

As cities grew, the walls of the cities could not follow the pace of urban development and keep on expanding, and urban functions were spread beyond the walls. Eventually, the great significance of the walls eroded away, but they did not become a thing of the past. As walls were coming down, others were rising within our environment. Throughout history, cities as centres of production and economy have been expanding to their surrounding areas and increasingly becoming subject to elements of divisions, that is, boundaries, segregations, and so on, which are either planned or not planned. Urban - and more generally, human affected - space, as Breitung (2012) puts it, is always made up of various boundaries which are created by administrative decisions, by processes of social or cultural segregation, by urban design, by the mental representation of space and human activity.

In fact, the notion of a human-affected environment today, is of an amalgam of physical and social entities. It is an ecological system with a very high entropy which evolves in space and time, and the changes of its parts/entities, as well as the relationships linking them, are hard to predict. Its part-whole 
relations are infinite and disturbance [or change] in one part affects the whole in non-linear unpredictable ways. In such a system, entities are defined by compositions of many different layers of human usage, and borders/barriers are socially produced and socially consumed. In fact, 'the boundary is not a spatial fact with sociological consequences, but a sociological fact that forms itself spatially' (Frisby and Featherstone 1997, p.142). Today, there are tangible walls and barriers, but with different social roles than the ones in the past, and also intangible boundaries of various types, delineating restricted places [enclosures within enclosures]. As Newman (2006) points out; "the "herethere" and "us-them" cut-off points are not always played out through the construction of physical and visible walls and fences. They may be as invisible as they are tangible and, equally, as perceived as they are real' (p.177).

Temporally, boundaries, walls, and borders exist and function over a period of time, but their form and function have to be in accordance to changes of conditions and events, and they can become abstract lines changing the social organizations and the interactions on either side. As Johnson et al. stress (2011), they are a pool of emotions, fears and memories that can be mobilized quickly. Consequently, the perception about boundaries of social groups or individuals who are related to them, affected by them, or just observing them, varies, as it is subjected to a continuous adaptation process to temporal, environmental, social and/or psychological changes, unique for each social group or individual. And since perceptions are the main motivations for the development of relations, and as space and place are based on relations, and relations change with perceptions, space and place are in constant flux (Deleuze and Guattari, 1988). In attempting a definition, the immured space provides the spatial framework and hosts the social interactions created by the effects of the tangible and intangible boundaries on human society.

\section{3. 'SPACE' AND 'PLACE': DEFINITIONS AND INTERRELATIONS}

The space/place that this work covers, is characterized by properties, which may be either tangible or intangible (or, in some cases, both) since our environment is composed of both, physical dimensions and perceptions that impact our assumed space. As Vis (2018) puts it, 'as perceivers and producers of the physical and social properties of the temporal and spatial environment we occupy, we both encounter and experience its properties through interaction' (p.78).

Since this work attempts to reconnect space and place theory to the study of cities and regions by probing the link between boundaries and restricted spaces in the human-affected environment, it is important that we also investigate the meaning of space and place within the context of this work. Space 
and place concepts have been varied throughout history, since our concepts of space and place develop and change in relation to the changing treatment and experience of space and place. What makes a place and what is a place and how a space becomes a space are all part of these variations of experience and treatment of place and space. Defining space and place in a human-made environment, and in particular, in an urban environment [city], and pinpointing differences in notions and functions is not an easy task. It seems that the assumed and often intuitive interdependency and interrelation of place and space becomes a precondition for their definition. Tuan (1977) asserts that 'the ideas "space" and "place" require each other for definition' (p.6), and that 'place is space infused by human meaning' and identifies 'space and place' as; '.. basic components of the lived world; we take them for granted. When we think about them, however, they may assume unexpected meanings and raise questions we have not thought to ask' (p.18).

Tuan then differentiates space as more abstract and he delineates place as an object which defines space, giving it a geometric dimension, and what initially appears as undifferentiated space, becomes place as we get to know it better and endow it with value. Yencken (1995) defines space as non-specific and available to everyone. Places, on the other hand, are 'immediate, known, and lived in. We move through spaces, we stop in and are directly involved with places' (Yencken in Winikoff, 1995, p.11). Furthermore, as Michel de Certeau denotes, place is also transitional where the meaning of place is never finished but is constantly being performed and re-formed (de Certeau, 1984). According to Lefebvre and Nicholson-Smith (1991) and Soja (1996) the geographical space is a social product (space of human activity), however, the production of space also implies the production of the meaning, concepts, and consciousness of space which are inseparably linked to its physical production. For Georg Simmel, 'space is a crucial and fundamental element in human experience because social activities and interactions are and must be spatially contextualised' (in Zieleniec, 2007, p.34). As Entrikin (1991) states, our ability to socially construct place enables us the freedom to create meaning and divides space into two dimensions; in pure objective representation of the material world and in subjective experiential interpretation of that world.

The notions of place and space in recent academic discourse also appear to be related to each other, and relative to the preceding discussions. For example, Seamon and Sowers (2008) emphasize that 'space and place are dialectically structured in human environmental experience, since our understanding of space is related to the places we inhabit, which in turn derive meaning from their spatial context' (p.44). Dovey (2009) then asserts that 'large part of what distinguishes place from space is that place has an intensity that connects sociality to spatiality in everyday life', which is again very similar to what Massey (1994, p.254) stated: 'the space is socially constructed and the social is 
spatially constructed too'. Similarly, Ben Hillier in his 'Space is the Machine' (2007, pp.18-19) mentions that 'most of our common notions of space do not deal with space as an entity in itself but tie it in some way to entities that are not space' and points to how we usually transcribe space as the 'use of space', 'the perception of space', or as ' concepts of space' where the idea of space is directly linked to human behaviour or human agent. Like the 17th-century mathematician and philosopher Leibniz ${ }^{2}$ (Leibniz, cited in Peters and Kessl, 2009, p.25) describes: 'the spatial definition is always from the position of the observer. If you change your position or your perspective, you will get a different spatial order'.

\section{THE IMMURED SPACE AS A THIRDSPACE}

Georg Simmel (1908) focuses on five basic properties of space, that is whether things, objects are fixed or mobile in space, whether they are near or far, how space can be open or closed, how it can separate or connect, and make things/ people insiders or outsiders by its boundaries (Zieleniec, 2007). In short, these comprise the exclusiveness or uniqueness of space, its boundaries, the fixing of social forms in it, its spatial proximity and distance and the movement of space. Simmel then goes on to add that boundary is a sociological function since space comes into being by giving form to a sensory material. Lefebvre on the other hand, distinguishes his socially constructed space in three categories which are the perceived space (i.e. spatial practices), the conceived space (i.e. spaces of representation), and the experienced space (i.e. representational spaces). Considering all the aforementioned definitions of space, it becomes clear that the interpretation of space is only possible from the perspective of social groups or individuals related, somehow to it, or just observing it. Moreover, this interpretation is usually associated with oppositional binaries which are not restricted to physical structures, but may be of social, economic, and political character, that define space.

Going a step further, Edward Soja (1996) develops the concept of thirdspace, and at the very beginning of his book Thirdspace explains that the overall aim of his work is: '... to encourage you to think differently about the meanings and significance of space and those related concepts that compose and comprise the inherent spatiality of human life: place, location, locality, landscape, environment, home, city, region, territory, and geography'. Furthermore, he goes beyond the traditional dualism and introduces the thirdspace as; 'a product of a "thirding" of the spatial imagination, the creation of another mode of thinking about space that draws upon material and mental spaces of the traditional dualism but extends well beyond them in scope, substance and meaning' (p.11). 
This work aims to follow Soja's suggestion and approach boundaries and restricted places through the notion of thirdspace, and thus, capture the 'constantly shifting and changing milieu of ideas, events, appearances, and meanings' (p.2). The signs that announce the name of the immured spaces or mark its boundaries are only visible when we encounter them. The immured space proposes a re-thinking of boundaries and restricted spaces by diverting from examining what they are or how they came about, and focusing on what they do or what they might do. This requires an examination of the social practices that feed into their production. These are spaces that are created by the non-recurrent, a-typical reaction of the space to boundaries, walls, or barriers and attain meaning from the part of the observer, ${ }^{3}$ whether practical or emotional.

The varied characteristics of immured space through time, location and social milieu, prevent us from synthesizing a basic model and explore how it connects with the other spaces and the relations between equivalent models. Nevertheless, immured space exists quite differently from the other spaces in incommensurable terms. The transition time between space and place is what gives meaning to the immured space. It is neither a space nor a place but a kairotic transcendence, a moment. Therefore, the immured space is a kind of thirdspace where time is in the space and space is in the time. With immured space time and space are contingent upon one another.

Spaces and places described and analysed in this work, are associated with boundaries or barriers, either of a physical or of immaterial nature, or of a combination of both. In the eyes of an observer they incorporate the element of the dualism between the immaterial/incorporeal and material/corporeal dimensions of spatiality. They are places created due to the restrictions or the boundaries in the background of the space. As Newman (2006) asserts these might be more 'fluid and elastic, easier to cross, than in the past, but they are out there all the same, impacting upon the minutiae of our daily life practices, identities and affiliations' (p.182).

Space immured is a space of collective characteristics, in or out of which free access or movement is denied, or forbidden, or strictly monitored for specific groups or individuals. In some cases, they are defined by a sense of intruding to an alien space which is imposed out of threat or fear. And sometimes they are spaces that we only understand their restrictions or boundaries when we encounter with them. In immured spaces barriers have clear and discrete characteristics. They can be physical or conceptual, and they are usually set by the 'dominant' of the involved groups or by a third agent or authority without consultation of all the involved agents, and often against the will of some of the involved. Their establishment or construction is time-independent. It might be an 'immediate' reaction to an incident like a war or social crisis, or a slow development reflecting the evolution of social gaps, conflicts or social segre- 
gation in an area. Examples such as the wall between Israeli and Palestinian land, or Donald Trump's planned one between the USA and Mexico, are quite indicative of the scope and nature of immured spaces.

An 'opening' of the barrier signifies the essential change of function of the immured space, and creates different dynamics, perceptions and attitudes, and reshapes the urban fabric. It is just the 'beginning of the end' of the immured space of this particular historic period. The physical barriers remain usually as remnants of their previous role and serve as historical elements and/or part of cultural tradition. Reflections of the boundaries in immured space are more obvious in the urban environment since human activities become more obvious, and social reproduction takes place there.

The book examines and analyses the origins of immured spaces and their nature, depending on a set of dualities and threshold of dualities (gradual or abrupt) which are defined as, for the purpose of this book, 'impermeable/permeable', 'trust/fear' and 'awe ( $\left.\delta \varepsilon \varepsilon_{0}\right)$ /foreboding'. Based on these, a categorization will be attempted with reflections at the three main functions of society: production, consumption, social reproduction. Emphasis will be given to the impact of immured spaces to perceptions and activities of the local populations and their reflections in the urban fabric (land uses, management of space, etc.).

The book consists of five parts, each of which, covers a distinct type of immured spaces, by providing examples/case studies from different parts of the world, which will be organized as chapters of each part. The coverage of all - or the most important and distinct - types of immured spaces aspires in contributing to the investigation and the designation of a common theoretical framework defining the notion of such spaces through time, space, and culture. In this sense, the theme of the book does not originate from theoretical perspectives, with policy making intentions, but provides a synthesis of real-life cases, which, after being explained and analysed, they knit a common canvas of the immured spaces. The parts of the book can be generally described as follows:

\section{PART I DIVIDED SPACES}

This part intends to focus on divided spaces, these extending from sectors within cities, to national territories. Barriers may actually be walls set because of political conflicts, or invisible barriers set by administrative regulations, cultural norms and differences, architectural styles, and physical barriers. National borders facing changes in uses, in through-communication, in effects on economic cohesion, and in people's perceptions, are also part of the divided spaces spectrum. The authors will discuss the impact of the division, as well as the impact of the reunification on the cities, the regional and national territo- 
ries, and the society. Therefore, the discussion should be based on the dualities based on ethnicity, religion, their effect on the city fabric and so on.

\section{PART II SEGREGATED SPACES}

This part aims to cover segregation of populations within the city (enclaves of the city) and processes for relative urban transformation. Spatial segregation is considered as the imposition by part(s) of the population with specific characteristics, of segregation on other part(s), based on equivalent characteristics (nationality, religion, legal status, gender, social class), often perceived as bearing threats for moral and cultural values, the quality, and the security/ safety of life in general, for the population groups imposing the segregation (pandemics etc.). Besides the classic domains of research on spatial segregation (architecture, urban planning, sociology), the approach through art, and particularly in urban science fiction films, constitutes another dimension examined in this part. The nature, structure, and means of boundaries of segregated spaces are also examined, in traditional but also in new forms (borders defined by postcodes).

\section{PART III PROTECTED SPACES}

This part aims to cover spaces that are accessed by only certain groups of people, and might be considered as the opposite but also complimentary to segregated spaces (in-space or out-space). The most characteristic examples are the protected neighbourhoods, residential states in many cities. These spaces are usually impermeable due to the dualities of fear/trust. Protected spaces are further analysed in terms of factors affecting their very nature and function, such as the visible/façade in the main street - back door/inner space, adequate lighting, unimpeded visual axis - dark spaces, interrupted visual axis, and so on. New forms of protected spaces are also examined, such as condominiums of specific types (park condominiums) which add new dimensions in the notion of protected spaces.

\section{PART IV SPACES BEYOND}

This part aims to cover the spaces that are connected or separated by feelings/ impressions of the unknown (e.g. threat, fear, trust) and the 'awe ( $\delta$ ćo $)$ /foreboding'. Typical examples of such spaces are spaces of living in relation to spaces of death, and also borders created by day and night. The authors may focus on necropolis, and its connection or disconnection to polis. This framework may include border of spaces, politics, management of cultural heritage and so on. 


\section{PART V CONNECTING THE DIVERSITY OF THE IMMURED SPACE}

This part aims to interrelate the theory of immured spaces given in the introduction with the case studies presented in previous chapters. The in-depth understanding of the very nature of immured space, as well as of the processes of their transformation may contribute in improvements and improvisations in policy making and in spatial planning in these areas.

\section{NOTES}

1. On 18 March 2016, the European Council and Turkey reached an agreement aimed at stopping the flow of irregular migration via Turkey to Europe. According to the EU-Turkey Statement, all new irregular migrants and asylum seekers arriving from Turkey to the Greek islands and whose applications for asylum have been declared inadmissible should be returned to Turkey. Source: https://www .europarl.europa.eu/legislative-train/theme-towards-a-new-policy-on-migration/ file-eu-turkey-statement-action-plan (accessed 17 February 2021).

2. German polymath and one of the most important logicians, mathematicians and natural philosophers of the Enlightenment.

3. By 'observer' we refer to social groups or individuals related to immured space, or just observing it.

\section{REFERENCES}

Breitung, W., 2012. Enclave urbanism in China: Attitudes towards gated communities in Guangzhou. Urban Geography, 33(2), pp.278-294.

de Certeau, M., 1984. The Practice of Everyday Life. Translated from French by Steven Rendall. Berkeley: University of California Press.

Deleuze, G. and Guattari, F., 1988. A Thousand Plateaus: Capitalism and Schizophrenia. London: Bloomsbury Publishing.

Dovey, K., 2009. Becoming Places: Urbanism/Architecture/Identity/Power. London: Routledge.

Entrikin, J.N., 1991. The betweenness of place. In: The Betweenness of Place. London: Palgrave, pp.6-26.

Frisby, D. and Featherstone, M. (eds), 1997. Simmel on Culture: Selected Writings. London: Sage.

Hillier, B., 2007. Space is the Machine: A Configurational Theory of Architecture. London: Space Syntax.

Johnson, C., Jones, R., Paasi, A., Amoore, L., Mountz, A., Salter, M. and Rumford, C., 2011. Interventions on rethinking 'the border' in border studies. Political Geography, 30(2), pp.61-69.

Lefebvre, H. and Nicholson-Smith, D., 1991. The Production of Space (Vol. 142). Oxford: Blackwell.

Newman, D., 2006. Borders and bordering: Towards an interdisciplinary dialogue. European Journal of Social Theory, 9(2), pp.171-186.

Massey, D., 1994. Space, Place and Gender. Cambridge: Polity Press. 
Mumford, L., 1961. The City in History: Its Origins, its Transformations, and its Prospects (Vol. 67). Boston, MA: Houghton Mifflin Harcourt.

Peters, M.A. and Kessl, F., 2009. Space, time, history: The reassertion of space in social theory. Policy Futures in Education, 7(1), pp.20-30.

Seamon, D. and Sowers, J., 2008. Place, and placelessness. In E. Relph (ed.), Key Texts in Human Geography. London: Sage, pp.43-51.

Simmel, G., 1908. The Sociology of Space. Translated from German by Mark Ritter \& David Frisby.

Soja, Edward W., 1996. Thirdspace: Journeys to Los Angeles and Other Real-and-Imagined Places. Cambridge, MA: Blackwell.

Tuan, Y.F., 1977. Space and Place: The Perspective of Experience. Minneapolis: University of Minnesota Press.

Vis, B.N., 2018. Cities Made of Boundaries: Mapping Social Life in Urban Form. UCL Press.

Yencken, D., 1995. Collaborating in placemaking. In T. Winikoff (ed.), Places Not Spaces, Placemaking in Australia. Sydney: Environbook, pp.11-13.

Zieleniec, A.J., 2007. Space and Social Theory. London: Sage. 